\title{
Electrical Investigation of the Mechanism of Water Adsorption/Desorption by Natural Clinoptilolite Desiccant Used in Food Preservation ${ }^{+}$
}

\author{
Gianfranco Carotenuto \\ Institute for Polymers, Composites, and Biomaterials (IPCB-CNR), National Research Council, \\ Piazzale E. Fermi, 1-80055 Portici, Italy; giancaro@unina.it \\ + Presented at the 2nd Coatings and Interfaces Web Conference, 15-31 May 2020; Available online: \\ https://ciwc2020.sciforum.net/.
}

Published: 21 April 2020

\begin{abstract}
Powdered zeolites are used as a desiccant in the preservation of many types of vegetable foods (e.g., cereal grain, corn, etc.). Natural clinoptilolite is a very abundant, inexpensive, nontoxic, regenerable, and environmentally friendly zeolite with good desiccant properties. Here, water adsorption/desorption properties of natural clinoptilolite have been investigated by a novel technique based on a.c. electrical measurements. In particular, owing to the presence of extraframework cations, zeolites are ionic conductors. The presence of water in cationic sites significantly modifies cation mobility, because strong electrostatic interactions act between cations and nucleophilic areas in 3D-frameworks, and non-hydrated cations have a near zero mobility, while hydrated cations have enough mobility at room temperature. The type of law controlling the adsorption/desorption process has been established by monitoring the real-time behavior of relative current intensity moving in the sample surface biased by a sinusoidal voltage signal of $20 \mathrm{~V}_{\mathrm{pp}}(5 \mathrm{kHz})$ and exposed to a constant moisture atmosphere $(75 \%)$ at $25^{\circ} \mathrm{C}$. An intergranular diffusion control was active at the beginning of hydration because of the lamellar texture, then Lagergren irreversible pseudo-first-order kinetics took place. To confirm the adsorption mechanism and possibility of regenerating the clinoptilolite desiccant, dehydration by silica gel was electrically monitored and an exponential kinetic law found.
\end{abstract}

Keywords: food preservation; zeolites; natural clinoptilolite; desiccant; water adsorption/desorption; electrical measurements; kinetics; zeolite hydration mechanism

\section{Introduction}

The study of natural functional nano-materials (i.e., functional nanostructured materials coming from nature) [1-3] is an emerging field in functional materials and nanotechnology science [4], which is based on the possibility of exploiting the nanoarchitecture of substances coming from the animal, vegetable, and mineral worlds, in the fabrication of novel types of devices. A number of biominerals and natural substances (e.g., halloysite, diatoms, zeolites, radiolars, etc.) have a microscopical structure characterized by tiny morphological features that can be advantageously exploited for functional applications in different technological fields (e.g., filtration, templating, sorption, fragrance release, drug delivery, etc.) [5]. A big potentiality of this approach is to develop environmentally safe and less harmful nanostructured materials compared to those produced by synthesis.

Natural zeolites are probably the most important types of natural substances with potentialities in functional application development. In fact, zeolites are solid-state ionic conductors with an 
electrical conductivity which strictly depends on the temperature and the presence of small polar molecules in their regularly porous crystal lattice. In fact, these two aspects of zeolites strongly influence the transport characteristics. These unique features of the zeolite structure, representable as a reverse of metallic lattice [6], with mobile positive charges (cations) and stationary delocalized negative charges (nucleophilic areas in the 3D-framework), are extremely useful specially in industrial engineering and technology. The ion movement is affected by the presence of an electric field, for example, that of an electromagnetic radiation and zeolites can even be of optical grade, making possible their use in sensors and optoelectronics fields. Never so many useful physical characteristics have been present in the same substance, that as a consequence can be used to fabricate sensors, batteries, capacitors, electroluminescent devices, etc.

Powdered zeolites have a very strong ability to physically adsorb gaseous water molecules and such a property has been industrially exploited in gas dehydration [7], water sensors [8], spontaneous insecticidal powders [9], humidity-control building materials [10], etc. However, the most important application of natural zeolite powders is as solid adsorbent for air dehumidification in food drying [11-13]. Zeolite powder is the most potentially useful adsorbent for enhancing food and agriculture drying. The high natural abundance, low cost, low toxicity, biocompatibility, low environmental impact, possibility of activation by heating to enhance as much as possible their ability to absorb water, recyclability, etc. make natural zeolite powder a very adequate drier for the preservation of some types of foods. In particular, the use of natural clinoptilolite powder has been proposed in the preservation of vegetables. Zeolites have also been used as desiccants for ethanol, drugs, electronics, etc. The comprehension of the mechanism involved in the physical adsorption of water molecules on zeolites is of a fundamental importance for the selection of the best zeolite-based desiccants (value of the $\mathrm{Si} / \mathrm{Al}$ ratio, type of extra-framework cations, pore size, dehydration temperature, etc.), their optimization (by ion exchange), and their adequate reactivation (by microwave heating, etc.). Some hypotheses on the way water molecules are adsorbed on zeolitic materials are available in the literature [14]; however, to the best of our knowledge, there is not an accepted model for this process and the exact pathway involved is unknown.

Here, the ability of a natural clinoptilolite sample to absorb water has been investigated by a novel approach based on electrical measurement, the kinetic of the process has been isothermally investigated in order to provide a hypothesis about the involved mechanism. The electrical method is based on the application of a sinusoidal voltage signal of constant amplitude $\left(20 \mathrm{~V}_{\mathrm{pp}}, 5 \mathrm{kHz}\right)$ to the clinoptilolite sample surface exposed to an environment with constant moisture (75\% by weight) and the analysis of the temporal evolution of the resulting current signal has provided kinetic information for the adsorption mechanism formulation. Some efforts in using electrical measurements to achieve information on the zeolite inner structure are reported in literature [15]; however, never has an electrical method been used to investigate the kinetics of water adsorption/desorption in zeolite and the kinetic information used for modeling the adsorption pathway. The sample surface has been morphologically characterized by scanning electron microscopy (SEM) before and after a mechanical fracturing aimed to delaminate the compact mineral structure and show the mineral texture.

\section{Materials and Methods}

A rectangular slab of natural clinoptilolite was obtained by cutting the raw stone (T.I.P. Technische Industrie Produkte $\mathrm{GmbH}$, Waibstadt, Germany) by a diamond saw (electric mini drill). A two-contact method was applied for the electrical characterization and silver paint (Enson, EN06B8) was used for contacting the sample surface. A sinusoidal voltage signal of $20 \mathrm{~V}_{\mathrm{pp}}$ and $5 \mathrm{kHz}$ was used to bias the sample surface, this signal was produced by a DDS function generator (GW Instek, SFG-1013), and the resulting current intensity was measured and recorded by using a True-RMS, 100 $\mathrm{kHz}$ bandwidth, micro-ammeter (Brymen, BM869s). The high frequency signal was required to avoid polarization of electrical contacts. The generator output power was high enough (ca. $40 \mathrm{~W}$ ), to allow to the voltage signal amplitude to remain practically constant during the full adsorption/desorption experiment. In fact, in such conditions, the current intensity is directly proportional to the charge carrier (cations) concentration. The sample was exposed to a constant humidity environment $(75 \%$ 
by weight), produced by the saturated salt method (wet $\mathrm{NaCl}$, at $25^{\circ} \mathrm{C}$ ) for hydration, while a sealed container, containing activated (blue) silica gel (that is, silica gel heated in air for $4 \mathrm{~h}$ at $120^{\circ} \mathrm{C}$ ), was used for sample dehydration.

The microstructure of the cut and fractured natural clinoptilolite sample surface was investigated by scanning electron microscopy (SEM, FEI Quanta 200 FEG microscope). Mechanical fracturing was achieved by applying an impact compressive stress (by hammer) to delaminate the compact mineral structure.

\section{Results}

The electrical characterization of the sample surface by means of planar electrodes allows one to limit the measurement of the clinoptilolite electrical property (e.g., current intensity, conductivity, etc.) approximately to only the surface and immediately sub-surface regions. Therefore, during sample exposition to a wet atmosphere, the temporal evolution of the surface current intensity is related to the physical adsorption of water molecules on the sample surface and precisely on: (i) the external surface of the clinoptilolite crystals and (ii) the exposed inter-granular regions present at the surface (zeolites are pyroclastic rocks and therefore have a granular structure). SEM investigation of the surface of a clinoptilolite slab did not clearly evidence the mineral structure (see Figure 1a), and consequently, the material was mechanically fractured by applying a compressive stress (hammer) to cause bulk delamination, and the achieved fragments were analyzed by SEM. On the other hand, to be used as desiccant a clinoptilolite needs to be in form of powder and, therefore, morphology has also been investigated in this form. As visible in Figure 1b, high magnification SEM-micrographs of the fractured mineral show that it is a finely-graining material of lamellar texture. In particular, it is made of separated plates with a thickness of $40 \mathrm{~nm}$ and the main sizes of a few microns, face-to-face arranged in blocks, and intergrain fractures, corresponding to mesopores, are present. For a perfectly dried sample, the water adsorption process should start on cations present at the surface of these intergrain fractures and, only after saturation of these regions, can the external crystal surface also be involved in the water adsorption process.

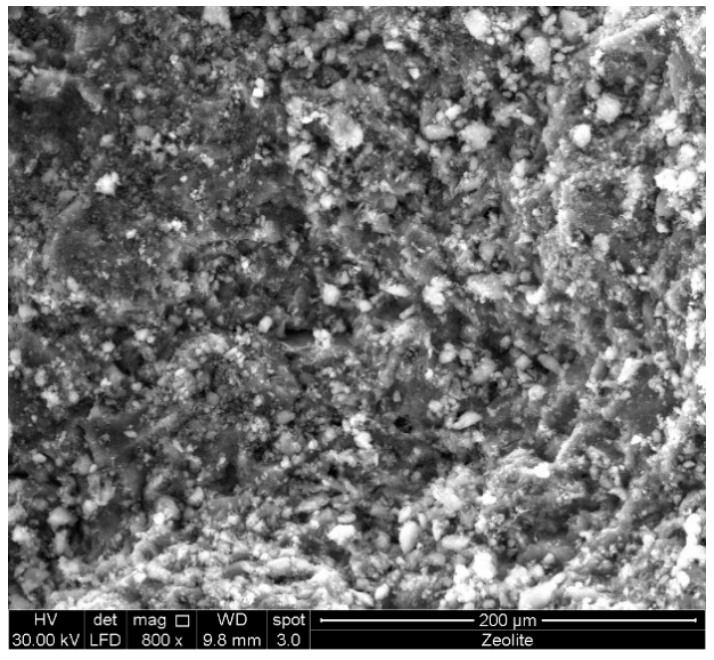

(a)

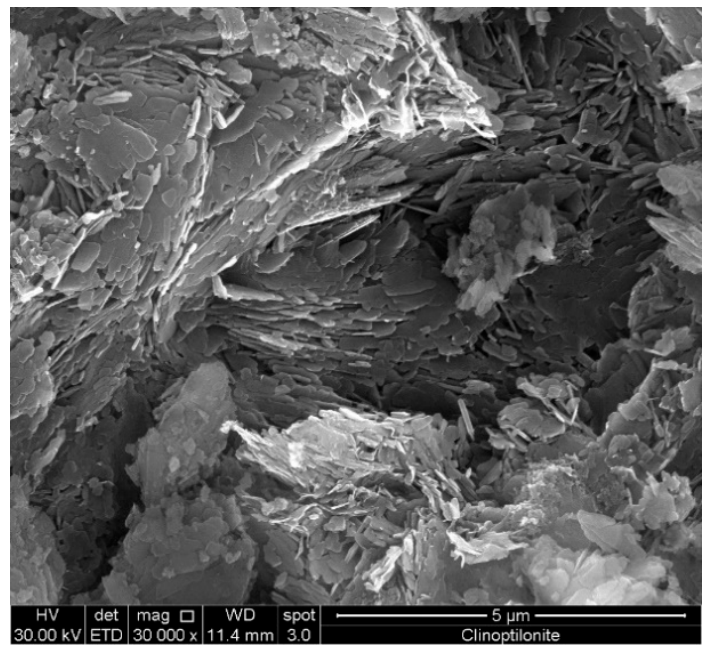

(b)

Figure 1. High magnification SEM-micrographs of the clinoptilolite sample surface cut by a diamond saw (a); and after delamination by mechanical fracturing (b).

In particular, fully desiccated samples were prepared by exposing the zeolitic material to wellactivated silica gel for a few days in a closed container. According to the electrical method, the current intensity, $\mathrm{I}$, measured during sample hydration, is directly proportional to the relative concentration

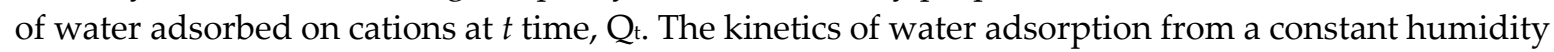
environment ( $75 \%$ by weight) by a perfectly dehydrated piece of natural clinoptilolite was found to be controlled by a diffusive mechanism. In fact, as visible in Figure 2, the concentration of water 
adsorbed on the surface of the natural clinoptilolite sample increased, during the exposition to constant humidity environment, linearly with $\sqrt{t}$.

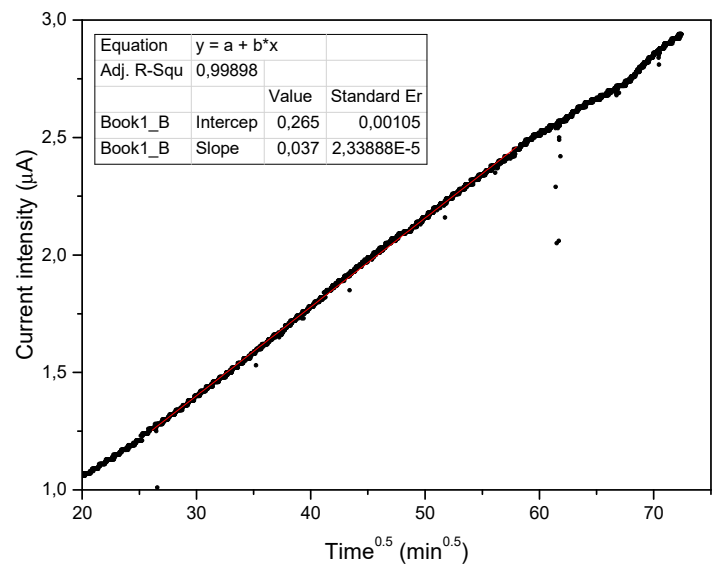

Figure 2. Behavior of the current intensity vs. $t^{1 / 2}$ during water adsorption by a fully dehydrated clinoptilolite sample.

Thus, the adsorption process can be described by the simple inter-granular diffusion (id) model:

$$
Q_{t}=k_{i d} \cdot t^{1 / 2}+C,
$$

where $k_{i d}$ is a measure of the diffusion coefficient and $C$ is the intra-particle diffusion constant [16]. According to this model, the adsorbate species are transported from the bulk of the gaseous phase to the solid phase by diffusion and this process is the rate-limiting-step. The linear best fitting gives: $k_{i d}=(3.70 \pm 0.002) 10^{-8} \mathrm{~A} \cdot \mathrm{min}^{-0.5}$ and an intercept value of $(2.65 \pm 0.01) \cdot 10^{-7} \mathrm{~A}$, with a determination coefficient $R=0.999$ (a $R$-value close to unity indicates the applicability of this model). The value found for the intercept is related to the average size of the inter-granular fractures [16].

Water molecules can be adsorbed both on cations present in the inter-granular regions (mesopores) and on those cations present at the crystal external surface. At the beginning, owing to the high diffusion rate, gaseous water near to the sample surface is almost exclusively depleted by an adsorption process, involving cations present in the inter-granular fractures. Only after these regions have been sufficiently saturated by water molecules, can the gaseous water start to be adsorbed on the external surface of the clinoptilolite crystals. In this case, the electrical method allows one to directly investigate the kinetics of the water-cationic site interaction. Since the adsorbate water fraction ( $\mathrm{f}$ ), that is, the ratio between the adsorbate concentration at $t$ time and equilibrium, $f=$ $Q_{t} / Q_{e}$, is coincident with the corresponding current intensity ratio, $I_{t} / I_{e q}$, the electric data can be used to establish the theoretical model of adsorption. As visible in Figure 3a, the adsorption process seems to follow the well-known pseudo-first-order irreversible model of Lagergren $[17,18]$, that can be expressed by using the following linear form:

$$
\log \left(1-\frac{I_{t}}{I_{e q}}\right)=\log \left(1-\frac{Q_{t}}{Q_{e q}}\right)=\frac{-k \cdot\left[H_{2} O\right]}{2.303} \cdot t,
$$

where $k$ is the rate constant of the pseudo-first-order irreversible adsorption $\left(\mathrm{min}^{-1}\right)$. In fact, a plot of $\log \left(1-I_{t} / I_{e q}\right)$ against $t$ has a linear behavior, the R-value (0.99973) close to unity indicates the validity of the model application, and $k$ can be determined from the slope. In particular, the slope is -0.00191 , and, because the water concentration corresponded to 0.75 by weight, the $k$ value is $(5.86 \pm 0.09) \times 10^{-3}$ $\min ^{-1}$. Owing to the presence of a constant humidity with a quite high value $(0.75 \%)$, the reverse process (desorption) does not take place, and, therefore, the irreversible Lagergren model can be adopted. 


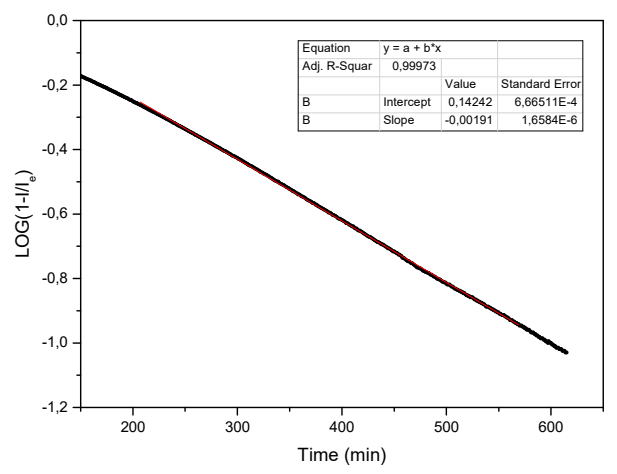

(a)

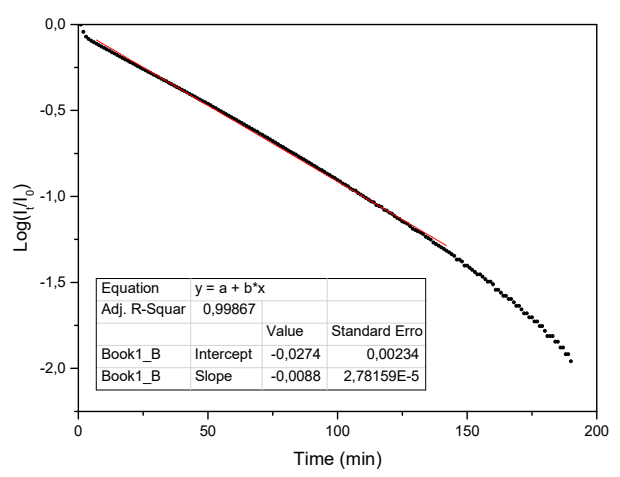

(b)

Figure 3. Fitting of the current intensity data by the pseudo-first-order irreversible model of Lagergren (a); and behavior of the relative current intensity logarithm during water desorption from a natural clinoptilolite sample $(\mathbf{b})$.

Figure $3 \mathrm{~b}$ shows the temporal behavior of the relative current intensity logarithm, which corresponds to the residual adsorbate fraction, $f=Q_{t} / Q_{0}=I_{t} / I_{0}$, during sample dehydration in dry air, produced by silica gel. Furthermore, in this case the reverse process cannot take place during dehydration. As visible, this quantity follows a linear behavior, thus indicating that the dehydration kinetics are described by a first-order kinetic model (the R-value is 0.999 , which is thus very close to unity, which indicates the feasibility of the first-order kinetic model).

$$
\log \left(\frac{I_{t}}{I_{0}}\right)=\log \left(\frac{Q_{t}}{Q_{0}}\right)=\frac{-k^{\prime}}{2.303} \cdot t,
$$

This type of model is typically observed in molecular release from zeolitic materials [19], and it corresponds exactly to the reverse of the model found for adsorption, thus confirming it. The slope of the linear curve gives the specific rate for dehydration in dry air, $k^{\prime}$, which has a value of $(2.027 \pm$ $0.003) \times 10^{-2} \mathrm{~min}^{-1}$. Since reverse processes do not take place during both adsorption and desorption, it is possible to calculate the equilibrium constant for the hydration process using the values found for the kinetic constants $\left(\mathrm{K}=k / k^{\prime}=0.29\right)$, and the standard free energy variation can also be calculated $\left(\Delta \mathrm{G}^{0}=-\mathrm{RT} \operatorname{lnK}=3.02 \mathrm{~kJ} \mathrm{~mol}^{-1}\right)$, which is positive, thus indicating that the hydration is not a spontaneous process.

According to this kinetic analysis, the rate-limiting-step for the adsorption process should involve a direct interaction between one water molecule and the cation (a pseudo-first-order is observed because the water concentration is a constant); this process takes place because of the electrostatic interaction between the water electric dipole moment and the cation electric field (cation-dipole interaction). However, to explain the promptly observed increase of cation mobility as a consequence of water adsorption, a second faster elemental step, based on a water molecule repositioning, should take place too. This second elemental step should involve the displacement of the water molecule at a framework-cation interface to maximize hydrogen bond interactions, with a consequent weakening of the cation-framework Coulomb interaction and an increase of the cation mobility. Thermodynamic considerations allow one to affirm that the adsorbed water is in equilibrium with environmental moisture and it spontaneously adsorbs/desorbs, depending on the environmental humidity level.

\section{Conclusions}

A kinetic analysis, based on time-resolved a.c. electrical measurements, has allowed us to formulate a hypothesis on the mechanism of water physical adsorption by zeolites. In particular, the water adsorption process on the external clinoptilolite crystal surface follows pseudo-first-order kinetics, while water desorption from this surface follows first-order kinetic behavior. Therefore, an elemental step involving a direct electrostatic interaction between cations and water molecules 
should be involved. On the other hand, in order to explain the strict dependence of cation mobility on the water adsorption process (increase of the sample electrical conductivity), a second faster elemental step, involving the water molecule displacement at framework-cation interface with increase of the cation mobility, could be hypnotized too. Such transfer of the water molecule takes place for thermodynamic reasons since, when the water molecule is placed at cation-framework interface, a large number of non-bonding interactions (electrostatic and hydrogen bonds) become possible.

Funding: This research received no external funding.

Conflicts of Interest: The authors declare no conflict of interest.

\section{References}

1. Hochella, M.F.; Spencer, M.G.; Jones, K.L. Nanotechnology: Nature's gift or scientists' brainchild? Environ. Sci. Nano 2015, 2, 114-119, doi:10.1039/C4EN00145A.

2. Morganti, P. Nanoparticles and Nanostructures Man-Made or Naturally Recovered: The Biomimetic Activity of Chitin Nanofibrils. J. Nanomater. Mol. Nanotechnol. 2012, 1, 1-4, doi:10.4172/2324-8777.1000101.

3. Ren, Z.; Guo, Y.; Liu, C.H.; Gao, P.X. Hierarchically nanostructured materials for sustainable environmental applications. Front. Chem. 2013, 1, 1-22, doi:10.3389/fchem.2013.00018.

4. Jeevanadam, J.; Barhoum, A.; Chan, Y.S.; Dufresne, A.; Danquah, M.K. Review on nanoparticles and nanostructured materials: History, sources, toxicity and regulations. Beilstein J. Nanotechnol. 2018, 9, 10501074, doi:10.3762/bjnano.9.98.

5. Kamble, R.; Ghag, M.; Gaikawad, S.; Panda, B.K. Halloysite nanotubes and applications: A review. J. Adv. Scient. Res. 2012, 3, 25-29.

6. Vucelic, D. Ionic conduction bands at zeolite interfaces. J. Chem. Phys. 1977, 66, 43-47, doi:10.1063/1.433608.

7. Firas, A.A.K.; Shariff, A.M.; Keong, L.K.; Mellon, N. Novel approach for $\mathrm{CO}_{2}$-enriched natural gas dehydration via adsorption using 13X zeolite as solid desiccants. Mater. Res. Innov. 2014, 18, S6-228-S6-231, doi:10.1179/1432891714Z.000000000961.

8. Sazama, P.; Jirglova, H.; Dedecek, J. Ag-ZSM-5 zeolite as high-temperature water-vapor sensor material. Mater. Lett. 2008, 62, 4239-4241, doi:10.1016/j.matlet.2008.06.037.

9. Kljajic, P.; Andric, G.; Adamovic, M.; Prazic-Golic, M. Possibilities of application of natural zeolites in stored wheat grain protection against pest insects. J. Process. Energy Agric. 2011, 15, 12-16.

10. Zhou, B.; Chen, Z. Experimental study on the hygrothermal performance of zeolite-based humidity control building materials. Int. J. Heat Technol. 2016, 34, 407-414, doi:10.18280/ijht.340309.

11. Djaeni, M.; Kurniasari, L.; Sasongko, S.B. Preparation of natural zeolite for air dehumidification in food drying. Int. J. Sci. Eng. 2015, 8, 80-83, doi:10.12777/ijse.8.2.80-83.

12. Djaeni, M.; Anggoro, D.; Santoso, G.W.; Agustina, D.; Asiah, N.; Hii, C.L. Enhancing the food product drying with air dehumidified by zeolite. Adv. J. Food Sci. Technol. 2014, 6, 833-838, doi:10.19026/ajfst.6.120.

13. Djaeni, M.; Kurniasari, L.; Purbasari, A.; Sasongko, S.B. Activation of natural zeolite as water adsorbent for mixed-adsorption drying. In Proceedings of the 1st International Conference on Materials Engineering (ICME) and 3rd AUN/SEED-Net Regional Conference on Materials (RCM), Yogyakarta, Indonesia, 25-26 November 2010.

14. Kalogeras, I.M.; Vassilikou-Dova, A. Electrical properties of zeolitic catalysts. Defect Diffus. Forum 1998, 164, 1-36, doi:10.4028/www.scientific.net/DDF.164.1.

15. Qiu, P.; Huang, Y.; Secco, R.A.; Balog, P.S. Effect of multi-stage dehydration on electrical conductivity of zeolite A. Solid State Ion. 1999, 118, 281-285, doi:10.1016/S0167-2738(98)00455-X.

16. Okewale, A.O.; Babayemi, K.A.; Olalekan, A.P. Adsorption isotherms and kinetics models of starchy adsorbents on uptake of water from ethanol-water systems. Int. J. Appl. Sci. Technol. 2013, 3, 35-42.

17. Tseng, R.L.; Wu, F.C.; Juang, R.S. Characteristics and applications of the Lagergren's first-order equation for adsorption kinetics. J. Taiwan Inst. Chem. Eng. 2010, 41, 661-669, doi:10.1016/j.jtice.2010.01.014. 
18. Shahwan, T. Lagergren equation: Can maximum loading of sorption replace equilibrium loading? Chem. Eng. Res. Des. 2015, 96, 172-176, doi:10.1016/j.cherd.2015.03.001.

19. Tekin, R.; Bac, N.; Warzywoda, J.; Sacco, A., Jr. Encapsulation of a fragrance molecule in zeolite X. Microporous Mesoporous Mater. 2015, 215, 51-57, doi:10.1016/j.micromeso.2015.05.020.

(C) 2020 by the authors. Licensee MDPI, Basel, Switzerland. This article is an open access article distributed under the terms and conditions of the Creative Commons Attribution (CC BY) license (http://creativecommons.org/licenses/by/4.0/). 